\title{
Jornalismo, política e despolitização: a homogeneidade dos jornais dominantes nas abordagens do Governo Dilma Rousseff
}

\section{Journalism, politics and depoliticization: the homogeneity of the approaches of Government Dilma Rousseff}

\author{
Antonio José Pedroso Neto* \\ Valmir Teixeira de Araújo ${ }^{\star \star}$
}

\begin{abstract}
Resumo: A midiatização da política é constitutiva do espaço político das sociedades democráticas. Há um modelo normativo típico que apresenta a relação da organização e da atividade econômica da imprensa com a política e a democracia, a partir de uma analogia com a concepção liberal da economia e da política. Há críticas a esse modelo: as pressões de mercado não levam à diversidade de conteúdo, ao pluralismo e à politização. Ao contrário, tendem a produzir a despolitização do campo do jornalismo e, assim, a homogeneização de conteúdo e a restrição do pluralismo. Objetivo deste artigo: colocar o problema para a imprensa brasileira e investigar 352 manchetes sobre o Governo Dilma nos jornais Folha de São Paulo, O Estado de São Paulo e O Globo. As análises de conteúdo e de enquadramento revelaram uma estrutura de homogeneidade de tomadas de posição dos jornais vis-à-vis à política: não há diversidade de conteúdo a dispor do espaço público. A midiatização da política tem significado restrição do universo dos possíveis com desdobramentos negativos para a democracia.
\end{abstract}

Palavras-chave: Despolitização. Dilma Rousseff. Jornalismo.

Abstract: The mediatization of politics is constituent of the political space of the democratic societies. There is a typical normative model which presents the relation of the organization and the economic activity of the press with politics and democracy through an analogy to the liberal conception of

\footnotetext{
* Pós-doutorado em Desenvolvimento Regional (FACE/CEDEPLAR/UFMG), Doutor em Ciências Sociais (UFSCAR) com estágio sanduíche no exterior (EHESS/Paris). Professor Associado I da UFT. Bolsista de produtividade do CNPq. Sociólogo. Pesquisador do Programa de Pós-Graduação em Desenvolvimento Regional (PPGDR/UFT) e do Programa de Pós-Graduação em Comunicação e Sociedade (PPGCOM/UFT). E-mail: ajpedrosoneto@uol.com.br

** Doutor em Comunicação Social (UMESB), mestre em Desenvolvimento Regional (PPGDR/UFT) e bacharel em Comunicação Social/Jornalismo (UFT). E-mail: valmir.ptu@gmail.com
}

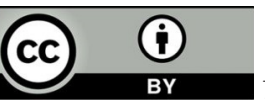


economy and politics. There is criticism to this model: the market pressures do not lead to the diversity of contents, pluralism and politicization. On the contrary, they tend to produce the depoliticization of the field of the journalism and, like this, the content homogenization and the restriction of the pluralism. Objective of this article: to put the problem to the Brazilian press and investigate 352 headlines about the Dilma government in the newspapers Folha de São Paulo, O Estado de São Paulo and O Globo. Content and framework analyses revealed a structure of homogeneity of the newspapers' position in relation to the politics: lack of diversity to the public space. The mediatization of politics has meaning restrictions of the universe of the possible ones with negative unfolding for the democracy.

Keywords: Depoliticization. Dilma Rousseff. Journalism.

Submetido em 23/09/2018. Aceito em 28/05/2020.

\section{Introdução}

A midiatização da política é constitutiva do espaço político das sociedades democráticas atuais e, de modo geral, há um modelo normativo típico que apresenta a relação da organização e da atividade econômica da imprensa com a política e a democracia, a partir de uma analogia com a concepção liberal da economia e da política. Há críticas a esse modelo e indicações de que, em seus desdobramentos, se encontra o problema da despolitização do campo do jornalismo expressa na homogeneização de conteúdo e restrição do pluralismo. Colocamos o problema para a imprensa brasileira, investigamos e apresentamos os resultados neste artigo ${ }^{1}$.

No Brasil, após a redemocratização e o retorno das eleições diretas nos anos 1980, houve a crescente presença e influência dos meios de comunicação no processo político e o aumento do número de pesquisas acadêmicas sobre mídia e política (RUBIM, AZEVEDO, 1998). Mas a questão da despolitização do espaço do jornalismo não está presente nesses estudos e está ausente nos mais recentes como, por exemplo, nos de Lourenço (2009) e Biroli e Mantovani (2010) sobre a produção da agenda nas campanhas; nos de Finamore, Carvalho e Hoff (2006) e Biroli (2010) sobre questões de gênero na mídia e na política; nos de Azevedo e Chaia (2008) sobre os editoriais dos jornais impressos relativos às ações dos agentes e das instituições legislativas; nos de Miguel (1999, 2003) e Azevedo $(2001,2006)$ sobre o comportamento e/ou a influência da mídia nos processos eleitorais; nos de Chaia e Teixeira (2001) e Grün (2008a, 2008b) sobre escândalos políticos, etc.

Alguns trabalhos abordaram a questão dos conteúdos veiculados: Biroli e Mantovani (2010) constataram a baixa pluralidade com observações empíricas em período de campanha eleitoral. Aldé, Mendes e Figueiredo (2007) pesquisaram a visibilidade, a valoração, etc. diferenciadas de

\footnotetext{
${ }^{1}$ Apresentamos dois esclarecimentos. Construímos o problema da pesquisa a partir de uma revisão da literatura internacional sobre despolitização e fizemos análises de dados empíricos. Esclarecemos que o ensaio completo sobre a revisão é de um dos autores deste artigo e já foi publicado (PEDROSO NETO, 2015). Sendo assim, a segunda seção deste artigo é parte da introdução daquele ensaio, após ligeiras modificações. Esclarecemos também que a totalidade das informações e dados da pesquisa empírica está em (ARAÚJO, 2014), pesquisa empírica de um dos autores deste artigo. Aproveitamos para agradecer à CAPES e ao CNPq pelo financiamento das pesquisas das quais saiu este artigo.
} 
candidatos a cargos eletivos na imprensa. Esses trabalhos são os mais próximos do tema deste artigo, mas, de fato, não entram na discussão da despolitização da política nas páginas dos jornais.

O objetivo desse trabalho foi investigar a despolitização na imprensa brasileira. A partir da perspectiva da "estrutura invisível e seus efeitos" (BOURDIEU, 1997, p. 55), colocamos para a imprensa escrita brasileira o problema da despolitização da política que se manifesta na tendência à homogeneização dos conteúdos. Os bens simbólicos sobre a esfera política - textos jornalísticos como artigos, reportagens, colunas, etc. - que são midiatizados pelos jornais impressos brasileiros são homogêneos? Para realizar a pesquisa, recorremos à análise dos conteúdos (BARDIN, 2011), dos enquadramentos (ENTMAN, 1993; GAMSON e MODIGLIANI, 1989; VAN GORP, 2007) e das editorias das manchetes principais sobre o Governo Dilma Rousseff (GDR) veiculados pelos três maiores jornais brasileiros, ou seja, os jornais dominantes: Jornal O Estado de São Paulo (JESP); Jornal Folha de São Paulo (JFSP); e Jornal O Globo (JOG). Os dados sobre tiragem, abrangência, etc. estão na seção abaixo.

A seguir, apresentaremos quatro seções. Uma sobre os acúmulos teóricos relacionados às relações entre mídia e política nas sociedades modernas e democráticas. Em seguida, uma sobre os procedimentos metodológicos, seguida por uma que apresenta as análises. Finalmente, tecemos algumas conclusões a título de considerações finais.

\section{Relações entre mídia e política: um modelo normativo e seus limites.}

Nas sociedades democráticas atuais, a visibilidade midiática e a agenda midiática são fundamentais para a construção e/ou desconstrução da imagem dos agentes e instituições políticas e, de modo algum, são desconsideradas por eles (CHAMPAGNE, 2015). Desde o desenvolvimento dos modernos meios de comunicação e de seus programas políticos, em grande medida houve "um deslocamento progressivo do centro de gravidade do espaço político, das assembleias parlamentares para as mídias" (CHAMPAGNE, 2015, p.147)2. Dito de outro modo, a vida política das sociedades democráticas está midiatizada: ela não acontece sem passar pela mediação dos meios de comunicação. Isso quer dizer também que não ocorre sem que os agentes e instituições do campo da política tenham alguma subordinação aos do campo do jornalismo, especialmente após os anos 1960 quando os jornalistas passaram a utilizar e produzir pesquisa de sondagens de opinião (BOURDIEU, 1997; THOMPSON, 1998b; NEVEU, 2000; CHAMPAGNE, 2015).

Desde o início da imprensa, há um modelo normativo típico que descreve/prescreve a relação da organização e da atividade econômica da imprensa com a política e a democracia. Depois de ser o grande marco de referência das lutas pela liberdade de imprensa, ainda no século XVIII, esse modelo perdura até os tempos atuais, porque estabelece o papel político da imprensa, a justificativa de sua existência para a sociedade. A dinâmica desse modelo parte de uma analogia com a concepção liberal da economia e da política. O registro deste esquema de pensar e de referência normativa - não sua realização empírica - está bem feito na literatura, por exemplo, em Schudson (1981, 2000), Thompson (1998a, 1998b), Horkheimer e Adorno (2002), Neveu (2006), dentre outros. Um pouco esquematicamente, é como segue.

Havendo liberdade de imprensa, é possível que a diversidade de pontos de vista sobre as diferentes dimensões da política tenha expressão, apareça no debate público. Assim se formam as opiniões públicas diversas - enriquece os conhecimentos e os debates políticos - que podem

${ }^{2}$ Tradução nossa de "un déplacement progressif du centre de gravité de l’espace politique, des assemblées parlementaires vers les médias” (CHAMPAGNE, 2015, p.147). 
controlar os abusos de poder dos governos que, por conta da liberdade de imprensa, estão expostos às críticas de suas atividades - a fórmula mítica do quarto poder a serviço dos cidadãos.

Essa liberdade de imprensa é viável dentro de uma forma de organização dos meios de comunicação; quando há multiplicidade de empresas privadas, diferentes, independentes e concorrentes. Assim, as empresas e os jornalistas são livres das intervenções do Estado e estão em concorrência entre si no plano econômico e no plano do conteúdo - competição de mercado.

A sociedade e a democracia se beneficiam das pressões competitivas, porque uma de suas consequências é colocar à disposição dos vários tipos de cidadãos uma diversidade de informações, pontos de vista, coberturas, possibilidades de expressão, etc. - diversidade que para os frankfurtianos é condição prévia de uma sociedade democrática (HORKHEIMER; ADORNO, 2002). Em uma fórmula simples: a livre iniciativa e a concorrência livre asseguram a expressão dos diversos pontos de vista possíveis e a independência vis-à-vis aos poderes econômicos e políticos - vale dizer autonomização profissional. Enfim, com esse modelo estamos diante de uma salvaguarda para a vida democrática.

Esse modelo normativo típico imperou no momento do nascimento da imprensa livre contra os constrangimentos dos Estados e da Igreja Católica (THOMPSON, 1998b) e permanece como referencial ainda que já fortemente criticado. Os frankfurtianos (HORKHEIMER, ADORNO, 2002) e Thompson (1998b), por exemplo, consideraram que a liberdade de empresas, em um ambiente de empresas privadas, implicou em efeitos negativos e ameaças à democracia, tanto por conta da grande concentração da propriedade dos meios de comunicação nas mãos de poucas e grandes indústrias multinacionais, como por conta do exercício restrito do poder estatal.

Mas há outro tipo de crítica a partir de constatações empíricas que teremos como referência neste texto. Na direção contrária ao modelo normativo típico, e nos trilhos de Schudson (1989), Champagne (1995), Bourdieu (1997) e Neveu (2006), seguimos a ideia de que as pressões de mercado não levam à diversidade de conteúdos e à politização. Ao contrário, elas tendem a reforçar a homogeneização de conteúdo e, assim, a despolitização da política nas páginas dos jornais, especialmente quando a pressão econômica é mais presente.

O principal fator é que, atualmente, as empresas privadas incontornavelmente dependem das receitas de publicidade e propaganda para gerirem suas atividades econômicas. Para acessar essas receitas, elas têm que apresentar os índices de audiência em níveis elevados, ou mais elevados que as concorrentes. Assim, aquelas que são dominantes nos respectivos campos - jornais e revistas impressas, rádio e, principalmente, a televisão - estão sempre em busca de maior índice de audiência, como podemos conferir em Schudson $(1981,2000)$ e Benson (2000) em relação aos EUA e em Champagne (1995, 2015) e Bourdieu (1997) em relação à França.

Para ter audiência, são obrigadas a seguirem caminhos semelhantes. Por um lado, alvejam o mesmo público; o maior público possível nos mesmos dias e horários. E, para isso, se orientam pelas mesmas categorias de classificação do público, tais como faixa etária, escolaridade, renda, etc. Por outro lado, acabam buscando o mesmo conteúdo mínimo, que é condição para conquistar e manter esse público (BOURDIEU, 1997).

Dito de outro modo, a concorrência as une e as leva a buscar e a publicar conteúdos imagens, textos, comentários, etc. - semelhantes: em um sentido, evitam temas que dividem o público, que sejam complexos, que tratem de conflitos políticos, que façam análises estruturais; em outro sentido, se concentram em conteúdos relacionados à natureza, a eventos chocantes, sensacionalistas, extraordinários (BOURDIEU, 1997). Enfim, impelidos pelo excepcional, extraordinário, exclusivo, "furo", os jornalistas, em grande medida, não produzem originalidade ou 
singularidades como se produz em outros campos, mas produzem a uniformização e a banalização de conteúdos (BOURDIEU, 1997).

Desde os anos 1970, progressivamente ocorre maior pressão do "campo econômico" (BOURDIEU, 2005) sobre o campo midiático, tanto por conta do deslocamento e ampliação dos recursos financeiros da publicidade em direção à televisão, como por conta de outros fatores; desregulamentações da profissão de jornalista, mudanças no mercado trabalho, fusões e concentração de propriedade das empresas de mídia, desestatização de empresas de mídia, entrada de empresas privadas no setor, etc. (CHAMPAGNE, 1995, BOURDIEU, 1997).

Neste contexto, nos últimos anos alguns fenômenos vêm se desenvolvendo em direção a promover uma despolitização da política, que tem duas características fundamentais: tendência à simplificação e à homogeneização do conteúdo. A simplificação é a tendência a resumir, abreviar, sensacionalizar e evitar assuntos ásperos no conteúdo jornalístico. Para atingir um público maior, relata-se menos, ou evita-se relatar situações conflituosas, estruturas de desigualdade - de gênero, partidárias, religiosas, raciais, etc. - explicações a partir de causas e conflitos estruturais e visões que socializam as causas e problemas, salvo quando há imagens e acontecimentos extraordinários, chocantes. Quer dizer, evita-se assuntos que dividem a audiência e que tenham efeitos políticos. E, assim, evita-se tomar posição política - criticar, apoiar, relatar sobre instituições ativas na vida política, como sindicatos, partidos, etc. - e toma-se distância da política, isto é, despolitiza-se o espaço do jornalismo e ao mesmo tempo despolitiza-se o debate público. A mesma tendência procura tratar de amenidades, oferecer informações políticas menos ásperas, oferecer uma visão funcional e consensual das relações e problemas sociais, procura apresentar conteúdos neutros, rasos, de fácil interpretação, que não exigem habilidade ou iniciação ao universo da política, livre de polêmica, etc. - falar do tempo, da natureza, etc. (CHAMPAGNE, 1995, 2015; BOURDIEU, 1997; KACIAF, 2003; SEDEL, 2013; SAÏTTA, 2014).

Outra característica da despolitização é a tendência à homogeneização do conteúdo, isto é, os temas, os assuntos, os agentes, as práticas, as instituições e os enquadramentos veiculados são cada vez mais os mesmos, inclusive as imagens e as fontes de informação - o que os frankfurtianos chamaram de homogeneizações típicas da indústria cultural (HORKHEIMER, ADORNO, 2002). Os jornais, a exemplo da televisão, mais e mais dependem e buscam a publicidade e, para isso, precisam de audiência. Por conta disso, acabam produzindo o mesmo conteúdo raso. Unidos na disputa, promovem uma homogeneização do espaço cognitivo midiático (CHAMPAGNE, 1995, 2015; BOURDIEU, 1997).

Enfim, passa-se de um leque aberto de possibilidades de comentar, tratar e analisar temas, agentes, instituições e práticas em conflito para um leque mais fechado, estreito e ameno. Dito de outro modo, simplificação e homogeneização implicam em fechamento do espaço dos possíveis que são ofertados aos leitores: menos eventos, instituições e agentes políticos sendo analisados; menos opiniões e visões diferentes dos eventos sendo apresentados e confrontados; menos grupos e agentes sociais diferenciados tendo espaço para expressão e voz. O pluralismo político nos jornais - diversidade de ideias e interesses dos cidadãos presentes nos mesmos - e a politização através dos meios de comunicação não decorrem das relações livres e concorrentes das empresas e dos jornalistas no mercado. Ao contrário, os constrangimentos do campo econômico via publicidade estão sancionando as empresas e os jornalistas para uma mesma direção e tornando homogêneos os "bens simbólicos" (BOURDIEU, 1974) que produzem, juntamente com o descarte das asperezas dos mundos social, econômico, político - representam um risco para a política e para a democracia (CHAMPAGNE, 1995; BOURDIEU, 1997). 


\section{Os jornais, as manchetes e os procedimentos metodológicos}

Observamos todas as capas publicadas pelos jornais dominantes em 2011, primeiro ano do primeiro mandato do GDR, e selecionamos para a análise todas as que fizeram referência ao GDR. Então, a partir de uma análise de conteúdo, de enquadramento (framing) e das editorias, foi possível averiguarmos o que eles noticiaram. Esses jornais têm abrangência nacional e possuem as maiores tiragens diárias. Outras características compartilhadas entre eles é que têm sede e sucursais no Rio de Janeiro, São Paulo e Brasília - os mais importantes centros urbanos do país, política e economicamente -, afora escritórios e freelances em diversas cidades, principalmente nas capitais estaduais; e são empresas comandadas por famílias. Os demais jornais impressos apresentam número de publicações diárias menores e não têm distribuição nacional na mesma proporção como, por exemplo, os jornais Zero Hora e o Diário Gaúcho, ambos de Porto Alegre, o Estado de Minas, de Belo Horizonte e o Correio Brasiliense, de Brasília. Ou têm tiragem maior, mas são locais. Por exemplo, o jornal Super Notícia, de Belo Horizonte, e o jornal Extra, do Rio de Janeiro.

Quadro 1 - A média de tiragem diária dos jornais

\begin{tabular}{|l|l|l|l|}
\hline Jornais/Ano & $\mathbf{2 0 1 0}$ & $\mathbf{2 0 1 1}$ & $\mathbf{2 0 1 2}$ \\
\hline JFSP & 294.498 & 286.398 & 297.650 \\
\hline JOG & 262.435 & 263.046 & 277.876 \\
\hline JESP & 236.369 & 256.259 & 235.217 \\
\hline
\end{tabular}

Fonte: Instituto Verificador de Circulação (IVC).

O objeto empírico foram as manchetes principais dos jornais dominantes durante o ano de 2011, doravante denominadas manchetes. A capa, ou a primeira página do jornal, correntemente é composta por fotos e chamadas, que são pequenos textos que resumem as notícias encontradas no interior do periódico. A partir das chamadas da capa, é possível detectar a relevância que o jornal atribui à determinada notícia, isto é, àquela que o corpo editorial elegeu como assunto de destaque e o jargão jornalístico chama de manchete principal (CHAMPAGNE, 2000; MELO, 2003). De modo geral, tais manchetes são apresentadas com letras garrafais acompanhadas por fotos e localizadas na parte superior da página (MELO, 2003).

Logo, para verificar os conteúdos e enquadramentos relativos ao GDR, observamos as manchetes como meio de inferir suas principais tomadas de posição. Observamos todas as edições dos jornais dominantes no ano de 2011 e selecionamos para o corpus de análise todas as manchetes que fizeram referência ao GDR: Governo Federal, Presidente e Vice-Presidente da República e Ministros. O corpus resultante tem 352 manchetes: 131 do JFSP, 115 do JOG e 106 do JESP.

A primeira análise do corpus incidiu sobre as editorias, isto é, sobre as seções dos jornais instituídas para separar os conteúdos por assuntos, assim como as equipes de jornalistas responsáveis por cada uma delas. Quais editorias foram responsáveis pelas manchetes? Respondemos à questão observando para qual editoria cada manchete encaminhava o leitor que quisesse continuar lendo a notícia.

A segunda investigação foi sobre as categorias de manchetes, ou seja, fizemos uma "análise de conteúdo categórica" (BARDIN, 2011) para classificar/categorizar as manchetes do corpus. Cada manchete é uma "unidade de contexto" (BARDIN, 2011). Realizamos uma "leitura flutuante" (BARDIN, 2011) de todas as unidades de contexto. A partir dessa leitura, construímos as categorias 
conforme um princípio básico: que cada uma tivesse um conteúdo exclusivo comparado a outras. O conteúdo de cada categoria são "unidades de registro" (BARDIN, 2011), ou seja, palavras ou temas que são exclusivos dela e que, assim, guiam a classificação de cada manchete em uma categoria exclusivamente. $O$ resultado foi um quadro com 18 categorias com suas respectivas unidades de registros ou conteúdos.

Em seguida, cada manchete foi lida e classificada como pertencente a uma categoria se contivesse as unidades de registro pertencentes a ela. Enfim, uma por uma, as 352 manchetes foram classificadas em 18 categorias.

Quadro 2 - As categorias

\begin{tabular}{|c|c|}
\hline Categorias & Unidades de registro: palavras e/ou temas. \\
\hline Salário-mínimo & $\begin{array}{l}\text { Proposta para salário-mínimo. Repercussão da proposta no Congresso. Votação e } \\
\text { atuação da oposição. }\end{array}$ \\
\hline $\begin{array}{l}\text { Gerenciamento } \\
\text { do Estado }\end{array}$ & $\begin{array}{l}\text { Manobras e estratégias relativas à administração pública. Questões salariais e de } \\
\text { benefícios para os servidores. }\end{array}$ \\
\hline Programas sociais & $\begin{array}{l}\text { Ações e projetos voltados para pessoas de baixa renda. Programas sociais. Discursos } \\
\text { sobre as questões sociais. }\end{array}$ \\
\hline $\begin{array}{l}\text { Articulações } \\
\text { políticas }\end{array}$ & $\begin{array}{l}\text { Eventos e questões partidárias. Relações políticas envolvendo a presidente ou os } \\
\text { ministros. As relações do Poder Executivo com os Poderes Legislativo e Judiciário e } \\
\text { com os governos estaduais. Questões relacionadas às emendas parlamentares. }\end{array}$ \\
\hline Política externa & $\begin{array}{l}\text { Ações e posições em relação ao posicionamento ou à soberania dos demais países ou } \\
\text { organismos internacionais, inclusive em relação a questões diplomáticas e de guerra. }\end{array}$ \\
\hline Segurança & $\begin{array}{l}\text { Panorama, propostas e ações sobre o setor de segurança pública envolvendo } \\
\text { diretamente o GDR, como as questões relacionadas às forças armadas e à Polícia } \\
\text { Federal. Questões relacionadas às fronteiras brasileiras e aos presídios federais. }\end{array}$ \\
\hline Meio Ambiente & $\begin{array}{l}\text { Ações, discursos e projetos voltados para impactos sobre meio ambiente. } \\
\text { Questões relacionadas à criação e à aprovação do Novo Código Florestal. Ações ou } \\
\text { posicionamentos relacionados a desastres ambientais. }\end{array}$ \\
\hline Educação & $\begin{array}{l}\text { Propostas e ações relacionadas ao setor de educação, básica ou superior. Questões } \\
\text { relacionadas ao Enem (Exame Nacional do Ensino). }\end{array}$ \\
\hline Corrupção & $\begin{array}{l}\text { Denúncias de corrupção como desvio de dinheiro público, propina, enriquecimento } \\
\text { ilícito, licitações fraudulentas e condutas congêneres dos membros do primeiro } \\
\text { escalão do GDR. Repercussão das denúncias no Congresso e no Judiciário. Ações dos } \\
\text { três poderes em relação às denúncias. }\end{array}$ \\
\hline Privatização & $\begin{array}{l}\text { Anúncios ou ações firmando parcerias com empresas privadas para realizarem } \\
\text { serviços, até então públicos, através de privatizações ou de concessões. }\end{array}$ \\
\hline Saúde & $\begin{array}{l}\text { Ações, anúncios e projetos voltados para o setor de saúde pública. Relações com o setor } \\
\text { de saúde: regulamentações do setor e relações como os planos privados de saúde. }\end{array}$ \\
\hline PIB & $\begin{array}{l}\text { Divulgação de dados sobre o crescimento, a estagnação e a recessão da economia } \\
\text { brasileira através dos números do Produto Interno Bruto (PIB). Divulgação da previsão } \\
\text { de crescimento do PIB, tanto por parte do GDR, como por instituições financeiras. }\end{array}$ \\
\hline Infraestrutura & $\begin{array}{l}\text { Questões relacionadas ao setor energético: apagões, crescimento da demanda de } \\
\text { energia, construção de hidrelétricas, construção de plataformas para extrair petróleo } \\
\text { e demais ações ou avaliação do GDR. Questões relacionadas ao setor de transportes: } \\
\text { trens, portos, aeroportos e rodovias. Programa de Aceleração do Crescimento (PAC). } \\
\text { Questões gerais relacionadas ao setor de infraestruturas e os problemas relacionados e } \\
\text { gerados. }\end{array}$ \\
\hline
\end{tabular}


conclusão

\begin{tabular}{|l|l|}
\hline Categorias & Unidades de registro: palavras e/ou temas. \\
\hline Inflação & $\begin{array}{l}\text { Questões relacionadas à alteração dos valores das mercadorias. As ações ou declarações } \\
\text { da presidente, dos ministros ou ainda divulgação de metas e análises sobre inflação. }\end{array}$ \\
\hline Finanças & $\begin{array}{l}\text { Questões relacionadas à situação econômica do GDR e do país. Atuação do GDR em prol } \\
\text { da situação financeira do país. Relações dos gestores com os números das bolsas de } \\
\text { valores. Questões de juros e investimentos do setor privado no território brasileiro. } \\
\text { Dívida externa e interna do Brasil. }\end{array}$ \\
\hline Tributos & $\begin{array}{l}\text { Propostas e ações do GDR relacionadas ao aumento ou diminuição, criação ou extinção } \\
\text { de tributos, impostos, taxas e contribuições. A repercussão dessas ações no Congresso. }\end{array}$ \\
\hline eventos & $\begin{array}{l}\text { Questões relacionadas às ações do GDR voltadas à realização da Copa do Mundo de } \\
\text { 2014 e às Olimpíadas de 2016. Posicionamentos do GDR relacionados às questões dos } \\
\text { ingressos e da legislação geral da Copa. Propostas do GDR para adaptações em prol dos } \\
\text { grandes eventos esportivos. }\end{array}$ \\
\hline Outros & $\begin{array}{l}\text { Assuntos relacionados ao GDR, mas não abarcados por uma das categorias: } \\
\text { aposentadorias, lei de acesso à informação, sigilo eterno dos documentos da ditadura, } \\
\text { privacidade da presidente, aprovação da presidente ou do governo, legislação sobre } \\
\text { comunicação e antifumo. Assuntos ambíguos que poderiam ser abarcados por mais de } \\
\text { uma categoria. }\end{array}$ \\
\hline
\end{tabular}

Fonte: Araújo (2014).

A terceira análise do corpus foi sobre os enquadramentos dados às categorias. A análise de conteúdo fornece a frequência de determinados temas e, assim, revela tomadas de posição dentre as possíveis. A análise de enquadramento permite tornar essa frequência mais matizada e, principalmente, revelar sentidos menos explícitos - prescrições, avaliações, princípios de classificação, princípios cognitivos de visão de mundo, etc. -, mas igualmente presentes nas "unidades de contexto" e que, em alguma medida, são políticas ou artifícios de tomada de posição dos jornalistas e de orientação e sensibilização de seus públicos para alguns aspectos em detrimento de outros.

Enquadrar é selecionar alguns aspectos de uma realidade percebida e torná-los mais salientes em um texto de comunicação, como meio de promover uma definição particular do problema, uma interpretação causal, uma avaliação moral e/ou uma recomendação de tratamento para o item descrito (ENTMAN, 1993, p. 52) ${ }^{3}$.

Desde Gamson e Modigliani (1989), Entman (1993) e Van Gorp (2007), ao menos, há o reconhecimento de que os bens simbólicos construídos pelos jornalistas procedem de seleções, arranjos e expressões de fatos, relações, informações, etc. orientados por "ideias organizadoras centrais" (GAMSON, MODIGLIANI, 1989) presentes na cultura de uma sociedade e, por isso, presentes nos momentos dos procedimentos comunicativos: seleção e observação dos acontecimentos; registro seletivo dos aspectos dos acontecimentos; redação e edição do texto divulgado; sensibilidade do leitor final.

Dito de outro modo, os produtos simbólicos dos jornalistas são gerados a partir de alguns princípios - e não de outros - que permitem compreender uma situação de uma determinada maneira e não de outra. Por exemplo, uma sequência de fotos com duas pessoas gesticulando

\footnotetext{
${ }^{3}$ Nossa tradução de "To frame is to select some aspects of a perceived reality and make them more salient in a communicating text, in such a way as to promote a particular problem definition, causal interpretation, moral evaluation, and/or treatment recommendation for the item described" (ENTMAN, 1993, p. 52, grifos do original).
} 
pode significar que estão brigando, mas se o observador sabe que as duas pessoas são amigas e comediantes enquadrará a situação como brincadeira.

Não foi possível fazer uma análise de enquadramento no sentido amplo que permite revelar sequências cognitivas recorrentes, por exemplo, de ordem moral, técnica, humorística, ou ainda "eleitoral" ou "política social" como observadas por Biroli e Mantovani (2010) em relação à cobertura do Programa Bolsa Família. O corpus de manchetes é constituído por textos curtos, basicamente frases. Então, optamos por classificar as manchetes a partir de enquadramentos positivos, negativos ou neutros dos agentes, acontecimentos e temas. Com essa análise nosso objetivo não foi tratar os assuntos a partir da perspectiva de que os jornais e jornalista tratam os acontecimentos com maior ou menor parcialidade, objetividade, manipulação, viés, etc. Como Hackett (1999), não reconhecemos validade nessa perspectiva. Mas classificar de algum modo um tipo de orientação de valor, de princípio, de visão de mundo, implícito nos bens simbólicos.

Optamos por analisar os enquadramentos presentes nas manchetes que a análise de conteúdo revelou como os mais frequentes no cômputo geral: corrupção, articulações políticas, inflação e finanças. Juntos, eles representam $56 \%$ das manchetes. E optamos por três registros de enquadramento: positivo, negativo e neutro. As unidades de registro de cada enquadramento relativo a cada categoria estão explicitadas no quadro abaixo e foram formadas a partir do mesmo procedimento supraexplicado; leitura flutuante e formação de categorias de enquadramento.

Quadro 3 - o quadro de enquadramentos

\begin{tabular}{|l|l|}
\hline Enquadramento & Elementos dos enquadramentos \\
& $\begin{array}{l}\text { De modo geral, manchetes que relatam: incapacidade do GDR de resolver problemas; } \\
\text { falta de domínio nas questões de governo; pouca efetividade e eficiências nas ações; } \\
\text { situações de derrota; situações que demonstram falta de comando; denúncias de } \\
\text { corrupção envolvendo os membros do GDR. } \\
\text { Articulações políticas: manchetes que relatam incapacidade de articulação política e } \\
\text { derrotas políticas. } \\
\text { Corrupção: manchetes que relatam o envolvimento com o desvio de dinheiro público, } \\
\text { com propina, com enriquecimento ilícito, com licitações fraudulentas, e que não } \\
\text { apresentem nenhuma conduta de efetividade do GDR contra tais práticas de seus } \\
\text { membros. } \\
\text { Inflação: manchetes relacionadas com o aumento dos valores dos produtos básicos de } \\
\text { consumo que é tratado como incapacidade e/ou falta de domínio do GDR. } \\
\text { Finanças: manchetes relacionadas à situação econômica do GDR e do Brasil, sobretudo } \\
\text { índices e indicadores financeiros que implicam em constrangimentos, entraves e } \\
\text { dificuldades para o crescimento e o desenvolvimento da economia. } \\
\text { Tributos: manchetes relacionadas às ações do GDR que enfatizam aspectos não } \\
\text { eficientes e não efetivos dos aumentos de tributos, impostos, taxas e contribuições. }\end{array}$ \\
\hline
\end{tabular}


conclusão

\begin{tabular}{|c|c|}
\hline Enquadramento & Elementos dos enquadramentos \\
\hline Positivo & $\begin{array}{l}\text { De modo geral, manchetes sobre ações do GDR que apresentem aspectos de domínio, } \\
\text { efetividade, eficiência, vitória, comando. } \\
\text { Articulações políticas: manchetes sobre negociações do GDR com os partidos, os } \\
\text { políticos e os outros poderes em que se evidenciou vitória do GDR. } \\
\text { Corrupção: manchetes sobre membros do GDR em atos de corrupção, mas que } \\
\text { relatam, sobretudo, ações efetivas do GDR no sentido de resolver o problema e punir os } \\
\text { envolvidos. } \\
\text { Inflação: manchetes relacionadas com a diminuição dos valores dos produtos básicos de } \\
\text { consumo e/ou da inflação. } \\
\text { Finanças: manchetes relacionadas à situação econômica do Brasil e do GDR apontado } \\
\text { para crescimento e desenvolvimento, sobretudo a dinâmica dos índices e indicadores } \\
\text { financeiros. } \\
\text { Tributos: manchetes relacionadas às ações do GDR que enfatizam aspectos eficientes e } \\
\text { efetivos da redução de tributos, impostos, taxas e contribuições. }\end{array}$ \\
\hline Neutro & $\begin{array}{l}\text { Manchetes que não possibilitam identificar enquadramentos positivos ou negativos, } \\
\text { como definidos acima, ou que apresentam uma situação de ambiguidade que não } \\
\text { permite serem classificadas em uma das duas opções de enquadramento. São casos } \\
\text { raros. }\end{array}$ \\
\hline
\end{tabular}

Fonte: Araújo (2014).

Novamente, cada manchete de cada uma das quatro categorias foi lida e classificada em uma das possibilidades de enquadramento, conforme contivesse as unidades de registro pertinentes.

Na próxima seção, apresentamos e discutimos os resultados, objetivando mostrar as singularidades e similaridades das tomadas de posição dos jornais dominantes em relação ao GDR.

\section{Hierarquia e frequência: editorias, temas e espaço nas manchetes.}

O dado mais geral é que os jornais dominantes dedicaram cerca de um terço de suas manchetes ao GDR. O JFSP foi o que mais divulgou tais manchetes: $37 \%$ do corpus e $36 \%$ da sua tiragem anual. Em seguida, está o JOG com 33\% do corpus e 32\% da tiragem anual. E, por fim, JESP com $30 \%$ do corpus e $29 \%$ da tiragem anual. Estruturalmente, podemos afirmar que a situação está muito próxima de uma cobertura homogênea.

A análise das editorias revelou que a maior parte das publicações remetia a duas editorias principais: editoria de política, $68 \%$; editoria de economia, $28 \%{ }^{4}$ - restando uma pequena parte para as demais editorias, $4 \%$. Verificamos que os jornais distribuíram as manchetes pelas duas editorias principais de modo semelhante. No que tange à editoria de política, a ordem é: JFSP, 70\%; JOG, 68\%; e JESP, 66\%. E, no que se refere à editoria de economia, a ordem é: JESP, 30\%; JOG, 28\%; e JFSP, 27\%. Enfim, podemos afirmar que, estruturalmente, os jornais dominantes mobilizaram suas editorias para tratar do GDR de modo homogêneo; concentram o assunto na editoria de política, principalmente, e na de economia.

A análise das categorias de manchetes revelou que os jornais dominantes compartilham também a frequência e a hierarquia de temas que exploram quando cobriram o GDR.

${ }^{4}$ No JFSP a editoria de política é chamada de "Poder" e a de economia de "Mercado". 
Tabela 1 - Categorias de manchetes

\begin{tabular}{|c|c|c|c|c|c|c|c|c|}
\hline \multirow{2}{*}{ Categorias } & \multicolumn{2}{|l|}{ JFSP } & \multicolumn{2}{|l|}{ JESP } & \multicolumn{2}{|l|}{ JOG } & \multicolumn{2}{|c|}{ Total } \\
\hline & Abs* & $\%$ & Abs & $\%$ & Abs & $\%$ & Abs & $\%$ \\
\hline Salário-mínimo & 1 & $1 \%$ & 2 & $2 \%$ & 5 & $4 \%$ & 8 & $2 \%$ \\
\hline Gerenciamento do Estado & 3 & $2 \%$ & 5 & $5 \%$ & 3 & $3 \%$ & $11 \%$ & $3 \%$ \\
\hline Programas sociais & 3 & $2 \%$ & 2 & $2 \%$ & 3 & $3 \%$ & 8 & $2 \%$ \\
\hline Articulações políticas & 7 & $5 \%$ & 17 & $16 \%$ & 11 & $10 \%$ & 35 & $10 \%$ \\
\hline Política externa & 5 & $4 \%$ & 7 & $7 \%$ & 2 & $2 \%$ & 14 & $4 \%$ \\
\hline Segurança & 3 & $2 \%$ & 0 & 0 & 6 & $5 \%$ & 9 & $3 \%$ \\
\hline Meio ambiente & 2 & $2 \%$ & 3 & $3 \%$ & 3 & $3 \%$ & 8 & $2 \%$ \\
\hline Educação & 3 & $2 \%$ & 0 & 0 & 1 & $1 \%$ & 4 & $1 \%$ \\
\hline Corrupção & 39 & $30 \%$ & 32 & $30 \%$ & 43 & $37 \%$ & 114 & $32 \%$ \\
\hline Privatização & 2 & $2 \%$ & 3 & $3 \%$ & 2 & $2 \%$ & 7 & $2 \%$ \\
\hline Saúde & 2 & $2 \%$ & 0 & 0 & 0 & 0 & 2 & $1 \%$ \\
\hline PIB & 5 & $4 \%$ & 3 & $3 \%$ & 1 & $1 \%$ & 9 & $3 \%$ \\
\hline Infraestrutura & 5 & $4 \%$ & 3 & $3 \%$ & 1 & $1 \%$ & 9 & $3 \%$ \\
\hline Inflação & 9 & $7 \%$ & 4 & $4 \%$ & 12 & $10 \%$ & 25 & $7 \%$ \\
\hline Finanças & 9 & $7 \%$ & 9 & $9 \%$ & 5 & $4 \%$ & 23 & $7 \%$ \\
\hline Tributos & 9 & $7 \%$ & 6 & $6 \%$ & 4 & $4 \%$ & 19 & $5 \%$ \\
\hline Eventos esportivos & 10 & $8 \%$ & 2 & $2 \%$ & 1 & $1 \%$ & 13 & $4 \%$ \\
\hline Outros & 14 & $11 \%$ & 8 & $8 \%$ & 12 & $10 \%$ & 34 & $10 \%$ \\
\hline Total & 131 & & 106 & & 115 & & 352 & \\
\hline
\end{tabular}

*Absoluto.

Fonte: Araújo (2014).

O dado mais importante, considerados os objetivos da pesquisa, é que os jornais compartilham uma cobertura destacada do tema "corrupção", seja porque a categoria representa de $30 \%$ a $37 \%$ em cada jornal, seja porque sua frequência é o dobro da frequência da segunda categoria mais recorrente, também em cada jornal: "articulações políticas" no JESP (16\%) e no JOG (10\%) e "eventos esportivos" no JFSP (5\%).

Dentre as dezoito categorias, as quatro com mais frequência no cômputo geral foram destacadas para a análise de enquadramento: "corrupção" (32\%), "articulações políticas" (10\%), "inflação" (7\%) e "finanças" (7\%). Somadas, elas representam 56\% do cômputo geral. Cada uma das quatro categorias principais tem frequência acima da média geral - 20 manchetes ${ }^{5}$ - e está entre as quatro ou seis categorias com mais frequência em cada jornal, salvo a categoria "outros": "corrupção" com 37\% no JOG e 30\% no JFSP e JESP; "articulações políticas" com 16\% no JESP, 10\% no JOG e 5\% no JFSP (esse jornal tem outras categorias com percentuais levemente maiores); "inflação" com 10\% no JOG, 7\% no JFSP e 4\% no JESP (os dois últimos jornais têm outras categorias com percentuais levemente maiores); e "finanças" com frequência de 9\% no JESP, 7\% no JFSP e $4 \%$ no JOG (os dois últimos jornais têm outras categorias com percentuais levemente maiores).

${ }^{5}$ Resultante da divisão do número total de publicações (352) pelo número de categorias (18). 
A análise dos enquadramentos dados aos principais assuntos - as quatro categorias principais - tratados pelas manchetes dos jornais dominantes também revelam uma estrutura de homogeneidade.

Como apresentamos acima, o assunto mais recorrente nas manchetes foi corrupção. Aparentemente, trata-se de um assunto negativo por si mesmo. Mas a análise demonstrou que não é assim necessariamente. Muitas vezes, os jornais relataram que o GDR teve iniciativas positivas em relação ao assunto; que demonstrou firmeza e domínio da situação, realizando demissões, punições e afastando os envolvidos de suas funções no governo.

Tabela 2 - Enquadramentos da categoria Corrupção

\begin{tabular}{l|l|l|l|l|l|l|l|l}
\hline \multirow{2}{*}{ Enquadramentos } & \multicolumn{3}{l}{ JFSP } & \multicolumn{3}{l}{ JESP } & JOG & \multicolumn{3}{l}{ Total } \\
\cline { 2 - 11 } & Abs* & $\mathbf{\%}$ & Abs & $\mathbf{\%}$ & Abs & \% & Abs & $\%$ \\
\hline Positivo & 1 & $3 \%$ & 5 & $16 \%$ & 4 & $9 \%$ & 10 & $9 \%$ \\
\hline Negativo & 36 & $92 \%$ & 25 & $78 \%$ & 36 & $84 \%$ & 97 & $85 \%$ \\
\hline Neutro & 2 & $5 \%$ & 2 & $6 \%$ & 3 & $7 \%$ & 7 & $6 \%$ \\
\hline Total & 39 & & 32 & & 43 & & 114 & \\
\hline
\end{tabular}

*Absoluto.

Fonte: Araújo (2014).

As manchetes da categoria "corrupção" foram predominantemente negativas (85\%). No JFSP, a frequência foi de $92 \%$. E foi um pouco menor no JOG (84\%) e no JESP (78\%). As manchetes enquadradas como negativas e neutras não apresentam fortes discrepâncias. 0 dado prevalecente é que os jornais, com ligeiras diferenças, compartilham o fato de que publicaram mais de três quartos de suas manchetes a partir de um enquadramento negativo, deixando o restante para os enquadramentos positivos e neutros.

A segunda categoria mais recorrente nas manchetes foi "articulações políticas". No cômputo geral, prevaleceu um enquadramento neutro (78\%) e duas partes, bem menores e iguais, de enquadramentos positivos e negativos, $11 \%$ cada.

Tabela 3 - Enquadramentos da categoria Articulações Políticas

\begin{tabular}{l|l|l|l|l|l|l|l|l}
\hline \multirow{2}{*}{ Enquadramentos } & JFSP & \multicolumn{3}{l}{ JESP } & JOG & \multicolumn{3}{l}{ Total } \\
\cline { 2 - 11 } & Abs* & \% & Abs & \% & Abs & $\%$ & Abs & $\%$ \\
\hline Positivo & 1 & $14 \%$ & 2 & $12 \%$ & 1 & $9 \%$ & 4 & $11 \%$ \\
\hline Negativo & 1 & $14 \%$ & 1 & $6 \%$ & 2 & $18 \%$ & 4 & $11 \%$ \\
\hline Neutro & 5 & $72 \%$ & 14 & $82 \%$ & 8 & $73 \%$ & 27 & $78 \%$ \\
\hline Total & 7 & & 17 & & 11 & & 35 & \\
\hline
\end{tabular}

*Absoluto.

Fonte: Araújo (2014).

Novamente ocorre o fato de que os jornais, com leves diferenças, compartilham a frequência dos enquadramentos, portanto pouca diversidade. Cerca de três quartos dos seus enquadramentos são neutros, e o restante se divide entre enquadramentos positivos e negativos. 
As categorias "finanças" e "inflação" compartilham o terceiro lugar de frequência nas manchetes, 7\% cada uma. E, também, são aquelas em relação às quais os jornais começam a apresentar diversidade quanto aos tipos de enquadramento que praticaram.

Tabela 4 - Enquadramentos da categoria Finanças

\begin{tabular}{l|l|l|l|l|l|l|l|l}
\hline \multirow{2}{*}{ Enquadramentos } & \multicolumn{3}{l}{ JFSP } & \multicolumn{2}{l}{ JESP } & \multicolumn{2}{l|}{ JOG } & \multicolumn{2}{l}{ Total } \\
\cline { 2 - 11 } & Abs* & $\mathbf{\%}$ & Abs & \% & Abs & \% & Abs & $\%$ \\
\hline Positivo & 3 & $33 \%$ & 1 & $11 \%$ & 0 & 0 & 4 & $17 \%$ \\
\hline Negativo & 1 & $11 \%$ & 0 & 0 & 0 & 0 & 1 & $4 \%$ \\
\hline Neutro & 5 & $56 \%$ & 8 & $89 \%$ & 5 & $100 \%$ & 18 & $78 \%$ \\
\hline Total & 9 & & 9 & & 5 & & 23 & \\
\hline
\end{tabular}

*Absoluto.

Fonte: Araújo (2014).

No cômputo geral dos enquadramentos do assunto "finanças", permanece a predominância de cerca de três quartos de um tipo de enquadramento; 78\% de neutro. Mas, diferentemente das duas categorias analisadas anteriormente, há uma discordância relevante entre os jornais. De um lado, o JESP e o JOG dedicam grande parte ou a totalidade de seus enquadramentos à neutralidade (89\% e 100\%, respectivamente) e o pouco restante ou nada aos enquadramentos positivos e negativos. Por outro lado, o JFSP dedica espaço relativamente menor para enquadramentos neutros (56\%) e relativamente maior para enquadramentos positivos (33\%) e negativos (11\%).

Os enquadramentos relacionados à categoria "inflação" acentuam as diferenças entre os jornais. No cômputo geral, permanece a predominância de um tipo de enquadramento sobre os outros, mas ela está abaixo de três quartos: $68 \%$ de negativo. A parte restante está dividida simetricamente entre enquadramentos neutros e positivos.

Tabela 5 - Enquadramentos da categoria Inflação

\begin{tabular}{l|l|l|l|l|l|l|l|l}
\hline \multirow{2}{*}{ Enquadramentos } & \multicolumn{3}{l}{ JFSP } & JESP & \multicolumn{2}{l}{ JOG } & \multicolumn{2}{l}{ Total } \\
\cline { 2 - 11 } & Abs* & $\mathbf{\%}$ & Abs & \% & Abs & \% & Abs & $\%$ \\
\hline Positivo & 0 & 0 & 2 & $50 \%$ & 2 & $17 \%$ & 4 & $16 \%$ \\
\hline Negativo & 7 & $78 \%$ & 1 & $25 \%$ & 9 & $75 \%$ & 17 & $68 \%$ \\
\hline Neutro & 2 & $22 \%$ & 1 & $25 \%$ & 1 & $8 \%$ & 4 & $16 \%$ \\
\hline Total & 9 & & 4 & & 12 & & 25 & \\
\hline
\end{tabular}

*Absoluto.

Fonte: Araújo (2014).

O JFSP compartilha com o JOG o predomínio do enquadramento negativo. E as semelhanças param por aí. Em seguida, cada um desses jornais vai dar mais relevância a enquadramentos diferentes: neutro (22\%) e positivo (17\%), respectivamente. O JESP dissona dos anteriores mais acentuadamente: deu enquadramento positivo à metade das manchetes e o restante igualmente dividido entre enquadramentos neutro e positivo.

Podemos afirmar que os jornais dominantes, em grande medida, compartilham os enquadramentos dados às suas manchetes uma vez que as categorias "corrupção" e "articulações políticas" reúnem $42 \%$ das manchetes e foram apresentadas a partir de enquadramentos semelhantes. As 
leves diferenças na frequência desses enquadramentos significam pouca diversidade ou muita homogeneidade. Em relação às categorias "finanças" e "inflação", registra-se aumento da diversidade de enquadramentos, mas, ainda assim, os jornais compartilham mais da metade da frequência de enquadramentos quando o assunto é "finanças" e dois deles compartilham mais de dois terços quando o assunto é "inflação".

Em síntese, com ligeiras diferenças, os jornais dominantes apresentam três dados estruturais: dedicam cerca de um terço de suas manchetes ao GDR; direcionam os leitores dessas manchetes às mesmas editorias - o que quer dizer também que são essas editorias que têm mais força interna nos jornais para impor um tema; compartilham uma hierarquia semelhante de frequência e enquadramento de temas sobre os quais produzem bens simbólicos relacionados ao GDR, inclusive a mesma amplitude de distância estatística entre a frequência da categoria mais recorrente e a frequência da subsequente. Esses dados caracterizam homogeneidade na cobertura e falta de diversidade disponível para os leitores ou o espaço público.

\section{Considerações Finais}

A pesquisa apresentada nos permite afirmar que a mídia impressa brasileira apresentou o primeiro ano do governo Dilma Rousseff de forma negativa. A sequência de análises demonstra um tratamento predominantemente homogêneo do principal agente político, a presidente da república. Também revela uma estrutura de homogeneidade de tomadas de posição em relação à política.

Essa estrutura se contrapõe à tese mítica de que o fortalecimento comercial, concorrencial e empresarial dos veículos de comunicação culminaria na diversidade de publicações à disposição no espaço público. Ela também permite concordar com a tese dos constrangimentos provocados pelas "estruturas invisíveis" (BOURDIEU, 1997): com o princípio de que tal fortalecimento leva à maior sujeição dos agentes e instituições aos congêneres do campo econômico, via busca de audiência para alcançar os recursos de publicidade - não é uma sujeição direta em forma de censura de quem paga.

A presença dessa estrutura de homogeneidade não é desprezível e pode ter desdobramentos negativos para os sistemas democráticos. Por um lado, significa que a midiatização da política no Brasil é constituída e reproduzida por estruturas que geram a despolitização da política e a restrição do universo das possíveis abordagens, o que é um tipo de censura. Por outro lado, revela objetivamente que o modo como os jornais dominantes no Brasil operam não é condizente com os ideais normativos e deontológicos dos jornalistas e com a função social que o grupo apresenta como justificativa para sua existência profissional, social e política. Para serem assim, teriam que demonstrar diversidade de coberturas, publicações, enquadramentos, pontos de vista, etc. e efetivar o ideal de que a pluralidade de ideias, valores, interesses, etc. dos cidadãos seria refletido na imprensa.

Esperamos ter contribuído com os conhecimentos científicos sobre os espaços político e midiático brasileiros, revelando estruturas que não têm a ver com ações orquestradas dos proprietários dos meios de comunicação de massa, como o senso comum erudito reverbera sem parar, contribuindo, sem o saber, para mantê-las veladas. Esperamos ter chamado a atenção para estruturas que merecem ser observadas e para que entre na agenda de pesquisas e discussões públicas outros pontos onde elas se manifestam: regulamentações/desregulamentações das instituições do espaço; distribuição dos recursos de publicidade e propaganda; formação, prática e 
regulamentação do trabalho profissional dos jornalistas; peso das relações intraorganizacionais na produção de agendas e notícias, etc.

\section{Referências}

ALDÉ, A.; MENDES, G.; FIGUEIREDO, M. Tomando partido: imprensa e eleições presidenciais em 2006. Política \& Sociedade, n. 10, 2007.

ARAÚJO, V. T. Enquadramentos do governo Dilma na mídia impressa brasileira. Dissertação (Mestrado em Desenvolvimento Regional). Universidade Federal do Tocantins, Palmas, TO, 2014.

AZEVEDO, F. A.; CHAIA, V. L. M. O Senado nos editoriais dos jornais paulistas (2003 2004). Opinião Pública, v. 14, n. 1, 2008.

AZEVEDO, F. A. Imprensa, cobertura eleitoral e objetividade: a eleição de 2000 na capital paulista. Opinião Pública, v. 7, n. 2, 2001.

AZEVEDO, F. A. Mídia e democracia no Brasil: relações entre o sistema de mídia e o sistema político. Opinião Pública, v. 12, n. 1, 2006.

BARDIN, L. Análise de conteúdo. Lisboa: Edições 70, 2011.

BENSON, R. La logique du profit dans lesv medias americains. Actes de la recherche em sciences sociales, Paris, v. 131-132, 2000.

BIROLI, F.; MANTOVANI, D. Disputas, ajustes e acomodações na produção da agenda eleitoral: a cobertura jornalística ao Programa Bolsa Família e as eleições de 2006. Opinião Pública, v. 16, n. 1, 2010.

BIROLI, F. Gênero e política no noticiário das revistas semanais brasileiras: ausências e estereótipos. Cadernos Pagu, n. 34, 2010.

BOURDIEU, P. O campo econômico. Política \& Sociedade, Florianópolis, n. 6, 2005.

BOURDIEU, P. O mercado dos bens simbólicos. In: A economia das trocas simbólicas. São Paulo: Perspectiva, 1974.

BOURDIEU, P. Sobre a televisão. Rio de Janeiro: Zahar, 1997.

CHAIA, V.; TEIXEIR, M. A. Democracia e escândalos político. São Paulo em Perspectiva, v. 15, n. 4, 2001.

CHAMPAGNE, P. La double dependance. Quelques remarques sur les rapports entre les champs politique, économique et journalistique, Hermes, Paris, 17-18, 1995.

CHAMPAGNE, P. Le mediateur entre deux Monde. Transformation du champ mediatique et gestion du capital journalistique. Actes de la recherche em sciences sociales, Paris, v. 131-132, 2000.

CHAMPAGNE, P. Faire l’opinion. Le neuveau jeu politique. Paris: Minuit, 2015.

ENTMAN, Robert. Framing: toward clarification of a fractured paradigm, Journal of Communication, n. 43, 1993.

FINAMORE, C. M.; CARVALHO, J. E. C.; HOFF, J. Mulheres candidatas: relações entre gênero, mídia e discurso. Revista Estudos Feministas, v. 14, n. 2, 2006. 
GAMSON, W.; MODIGLIANI, A. Media discourse and public opinion on nuclear power: a constructionist approach. American Journal of Sociology, v. 95, n. 1, 1989.

GRÜN, R. Escândalos, marolas e finanças: para uma sociologia da transformação do ambiente econômico. Dados, v. 51, n. 2, 2008a.

GRÜN, R. Guerra cultural e transformações sociais: as eleições presidenciais de 2006 e a "blogosfera". Sociedade e Estado, v. 23, n. 3, 2008b.

HACKETT, R. A. Declínio de um paradigma? A parcialidade e a objetividade nos estudos dos media noticiosos. In: TRAQUINA, N. (Org.). Jornalismo: questões, teorias e "estórias". Lisboa: VEJA, 1999.

HORKHEIMER, M.; ADORNO, T. A indústria cultural: o iluminismo como mistificação de massas. In: LIMA, L. C. (Org.). Teoria da cultura de massa. São Paulo: Paz e Terra, 2002.

KACIAF, N. Les Pages "politique". Histoire du journalisme politique dans la presse écrite française (1945-2006). Rennes: PUR, 2003.

LOURENÇO, L. C. Propaganda negativa: ataque versus votos nas eleições presidenciais de 2002. Opinião Pública, v. 15, n. 1, 2009.

MELO, J. M. Jornalismo opinativo: gêneros opinativos no jornalismo brasileiro. Campos do Jordão: Mantiqueira, 2003.

MIGUEL, L. F. A eleição visível: a Rede Globo descobre a política em 2002. Dados, v. 46, n. 2, 2003.

MIGUEL, L. F. Mídia e eleições: a campanha de 1998 na Rede Globo. Dados, v. 42, n. 2, 1999.

NEVEU, E. De quelques effets des processos de mediatisation sur la democraties contemporaines.

Réseaux, Paris, v. 18 n. 100, 2000.

NEVEU, E. Sociologia do jornalismo. São Paulo: Loyola, 2006.

PEDROSO NETO, A. J. Jornalismo e despolitização. Revista Observatório, v. 1, p. 82-100, 2015.

RUBIM, A. A. C.; AZEVEDO, F. A. Mídia e política no Brasil. Lua Nova, São Paulo, n. 43, 1998.

SAÏTTA, E. Les transformations du rapport à la politique des journalistes français et italiens. Savoir/ Aagir, Paris, n. 28, 2014.

SCHUDSON, M. Discovering the news. New York: Basic Books, 1981.

SCHUDSON, M. The power of news. Cambridge: Harvard University Press, 2000.

SCHUDSON, M. The sociology of news production. Media Culture Society, London, v. 11, 1989.

SEDEL, J. Les médias et la banlieue. Paris: Le Bord de Le Eau, 2013.

THOMPSON, J. B. Ideología y cultura moderna. Ciudad de México: Universidad Autónoma Metropolitana, 1998a.

THOMPSON, J. B. Los media y la modernidad. Barcelona: Paidós, 1998b.

VAN GORP, B. The constructionist approach to framing: bringing culture back, Journal of communication, n. 57, 2007. 